\title{
RNA-binding protein A1CF modulates plasma triglyceride levels through posttranscriptional regulation of stress-induced VLDL secretion
}

Running Title: Lin et al.; A1CF in Triglyceride Metabolism

Jennie Lin, ${ }^{1,2^{*}}$ Donna M. Conlon, ${ }^{3 *}$ Xiao Wang, ${ }^{4 *}$ Eric Van Nostrand, ${ }^{5}$ Ines Rabano, ${ }^{5}$ YoSon Park,${ }^{6}$ Alanna Strong, ${ }^{7}$ Behram Radmanesh, ${ }^{1}$ Yoseph Barash, ${ }^{6}$ Daniel J. Rader, ${ }^{3,6,7}$ Gene W. Yeo, ${ }^{5}$ and Kiran Musunuru ${ }^{4,6}$

${ }^{1}$ Division of Nephrology and Hypertension and ${ }^{2}$ Feinberg Cardiovascular and Renal Research Institute, Northwestern University Feinberg School of Medicine, Chicago, IL, USA

${ }^{3}$ Division of Translational Medicine and Human Genetics of the Department of Medicine, Perelman School of Medicine at the University of Pennsylvania, Philadelphia, PA, USA

${ }^{4}$ Cardiovascular Institute of the Department of Medicine, Perelman School of Medicine at the University of Pennsylvania, Philadelphia, PA, USA

${ }^{5}$ Department of Cellular and Molecular Medicine, University of California San Diego, La Jolla, CA, USA

${ }^{6}$ Department of Genetics, Perelman School of Medicine at the University of Pennsylvania, Philadelphia, PA, USA

${ }^{7}$ Division of Human Genetics, Children's Hospital of Philadelphia, Philadelphia, PA, USA

*These authors contributed equally.

Address correspondence to:

Jennie Lin, 303 East Superior Street, Lurie 10-109, Chicago, IL 60611 USA. Phone: 312-503-1892; Fax: 312-503-0137; E-mail: jennie.lin@northwestern.edu

Kiran Musunuru, Smilow Center for Translational Research, Room 11-102, 3400 Civic Center Boulevard, Philadelphia, PA 19104, USA. Phone: 215-573-4717; Fax: 215-746-7415; E-mail: kiranmusunuru@gmail.com.

Total Word Count: 9,162 


\section{ABSTRACT}

2 Background - A recent human exome-chip study on plasma lipids identified a missense mutation in the

3 AICF (APOBEC1 complementation factor) gene that is associated with elevated triglyceride (TG) levels,

4 but how A1CF, an RNA binding protein, influences plasma TG is unknown.

5 Methods - We generated $A 1 c f$ knockout $\left(A 1 c f^{--}\right)$mice and knock-in mice homozygous for the TG-

6 associated Gly398Ser mutation $\left(A 1 c f^{\mathrm{GS} / \mathrm{GS}}\right)$, determined lipid phenotypes, and assessed TG physiology

7 through measurements of clearance and secretion. We further identified A1CF's RNA binding targets

8 using enhanced cross-linking and immunoprecipitation sequencing of cultured HepG2 cells and

9 investigated pathways enriched for these targets. Transcriptomic effects of A1CF deficiency were

10 evaluated through RNA sequencing and analyses for differential expression, alternative splicing, and

11 RNA editing.

12 Results -Both $A 1 c f^{-/-}$and $A 1 c f^{G S / G S}$ mice exhibited increased fasting plasma TG, establishing that the TG

13 phenotype is due to A1CF loss of function. In vivo TG secretion and clearance studies revealed increased

14 TG secretion without changes in clearance in $A 1 c f^{-/}$mice. Increased VLDL-apoB secretion was also

15 seen in $A 1 C f^{-/-}$rat hepatoma cells, but no increase in apoB synthesis was observed. This phenotype was

16 seen without significant shifts in apoB-100/apoB-48 in A1CF deficiency. To discover novel pathways for

17 A1CF's role in TG metabolism, we identified A1CF's RNA binding targets, which were enriched for

18 pathways related to proteasomal catabolism and endoplasmic reticulum (ER) stress. Indeed, proteasomal

19 inhibition led to increased cellular stress in $A 1 \mathrm{Cf}^{-/-}$cells, and higher expression of ER-stress protein

20 GRP78 was observed in resting $A 1 c f^{-/-}$cells. RNA-seq of whole livers from wild-type and $A 1 c f^{-/}$mice

21 revealed that pro-inflammatory, not lipogenesis, genes were upregulated as a secondary effect of A1CF

22 deficiency. Differential alternative splicing (AS) analysis and RNA editing analysis revealed that genes

23 involved in cellular stress and metabolism underwent differential changes in A1CF deficiency, and top

24 A1CF binding target proteins with relevance to intracellular stress were differentially expressed on the

25 protein but not mRNA level, implicating multiple mechanisms by which A1CF influences TG secretion. 
1 Conclusions - These data suggest an important role for A1CF in mediating VLDL-TG secretion through

2 regulating intracellular stress.

4 INTRODUCTION

5 Large-scale human genetics studies have identified DNA variants at novel genomic loci associated with

6 cardiometabolic traits, including blood lipid levels ${ }^{1-7}$. One of the strongest novel findings from a recent

7 exome-sequencing study on lipid traits was an association between plasma triglycerides (TG) and the

8 low-frequency variant rs41274050 (chr10: 52573772, hg19), a Gly398Ser (GS) missense mutation in the

9 AICF (APOBEC1 complementation factor) gene ${ }^{8}$.

10 Although the A1CF protein has been studied in the context of apolipoprotein B (apoB)

11 production, its precise function in TG metabolism still remains elusive. As an RNA binding protein

12 (RBP) expressed in the liver, small intestines, and kidneys (Supplemental Figure 1A), A1CF was

13 originally discovered in the context of binding $A P O B$ mRNA and complexing with the RNA editing

14 enzyme APOBEC1 to facilitate editing of the $A P O B$ transcript. This interaction induces the deamination

15 of cytidine ${ }^{6666}$ to uridine, thus converting the glutamine codon 2153 (CAA) to an in-frame stop codon

16 (UAA) that generates apoB's B-48 isoform ( $48 \%$ the length of the full B-100 isoform) ${ }^{9-14}$. Previous

17 reports have shown that loss of APOBEC1 function in mice does not affect circulating TG levels ${ }^{15,16}$,

18 suggesting that A1CF's role in modulating plasma TG extends beyond its interaction with APOBEC1 and

19 apoB-48 production.

In this study, we explored A1CF's contribution to TG metabolism through an integrated unbiased

21 discovery approach. We found in our genetic mouse models that the GS mutation results in a lipid

22 phenotype consistent with A1CF loss of function, without shifts in B-100/B-48 ratios. To identify A1CF's

23 RNA binding targets outside of $A 1 C F$ mRNA, we performed enhanced cross-linking and

24 immunoprecipitation (eCLIP) followed by sequencing in HepG2 cells. Additionally, we performed

25 unbiased transcriptome profiling to evaluate how A1CF interacts with mRNA transcripts to promote the 
1 TG phenotype. Through these profiling efforts we identified many RNA binding targets outside of $A P O B$

2 mRNA and also discovered a novel role for A1CF as an RNA splicing regulator. Ultimately, we found

3 that through multiple mechanisms A1CF mediates intracellular stress and subsequent VLDL secretion.

\section{METHODS}

6 Expanded Methods are available in the Online Data Supplement.

\section{$7 \quad$ Experimental animals}

8 Homozygous $A 1 c f$ knockout $\left(A 1 c f^{--}\right)$and mice harboring the $A 1 c f$ GS mutation $\left(A 1 c f^{\mathrm{GS} / \mathrm{GS}}\right)$ were

9 generated using CRISPR-Cas9 genome editing, as described previously ${ }^{8}$. Briefly, to create both mouse

10 strains simultaneously, we generated an in vitro transcribed CRISPR guide RNA (gRNA) targeting exon

119 of Alcf, which harbors the site of the Gly398Ser mutation. To knock in the Gly398Ser mutation, we

12 also generated a 200-nucleotide single-stranded DNA oligonucleotide (ssODN) with homology to the

13 mutation and other synonymous variants to prevent CRISPR-Cas9 re-cleavage of knock-in alleles. The

14 Harvard Transgenic Core co-injected the gRNA and the ssODN with a Cas9-expressing mRNA into

15 approximately 200 one-cell embryos of the C57BL/6J background (Jackson Laboratory). Following

16 implantation of the embryos into surrogate mothers, approximately 50 mice were born, of which the

17 majority harbored insertions and deletions (indels) while a few had Gly398Ser knock-in alleles (Figure 1).

18 All mice were fed ad libitum with chow diet and fasted overnight prior to blood collection for plasma

19 lipids, unless stated otherwise. Blood was collected through tail-vein puncture into heparin-lined tubes;

20 blood samples were then centrifuged to obtain the plasma portion. Baseline plasma lipid and ALT levels

21 were analyzed on an AXCEL autoanalyzer using commercially available reagents (Sigma Aldrich).

22 Plasma total cholesterol (TC) and TG were also measured via calorimetric assay (Infinity reagents,

23 Thermo Fisher) for samples collected during in vivo experiments.

\section{Generation and culture of A1CF-deficient McArdle cells}


1 McArdle RH-7777 (McA) rat hepatoma cells (ATCC) were maintained in Dulbecco's Modified Eagle

2 Medium (Gibco) with 10\% fetal bovine serum, 10\% horse serum, and 1\% penicillin-streptomycin. The

3 same guide RNA protospacer sequence used to generate $A l c f^{-/}$and $A l c f^{\mathrm{GS} / \mathrm{GS}}$ mice was inserted into

4 pGuide (Dr. George Church, http://www.addgene.org/64711/). The guide RNA plasmid was co-

5 transfected with pCas9_GFP (http://www.addgene.org/44719/) into McA cells with Lipofectamine 3000

6 (Thermo Fisher) according to the manufacturer's protocol. After 48 hours, cells were subjected to

7 fluorescent activated cell sorting (FACSAria II) to isolate GFP-positive cells that were then plated at low

8 density in $10 \mathrm{~cm}$ dishes to encourage formation of pure colonies from single-cell clones. Genomic DNA

9 was extracted from colonies using the DNeasy Blood \& Tissue Kit (Qiagen), and Alcf exon 9 was PCR

10 amplified for Sanger sequencing to confirm the presence of indels. Clones with indels that shift the

11 reading frame were selected for continued culture and cell experiments.

\section{3 eCLIP-seq of HepG2 cells}

14 eCLIP was performed as previously described ${ }^{17}$. Briefly, A1CF-RNA interactions in $20 \times 10^{6}$ HepG2

15 cells were stabilized with UV crosslinking $\left(254 \mathrm{~nm}, 400 \mathrm{mg} / \mathrm{cm}^{2}\right)$. Crosslinked cells were then lysed, with

16 limited digestion of RNA with RNase I (Ambion). A1CF-RNA complexes underwent

17 immunoprecipitation with an A1CF antibody (Abcam ab89050) using magnetic beads coupled with

18 secondary antibody against Protein A. After stringent washes and dephosphorylation with FastAP

19 (Thermo Fisher) and T4 PNK (NEB), a barcoded RNA adapter was ligated to the 3' end on-bead with

20 PEG8000. Samples were run on standard protein gels and transferred to nitrocellulose, with a region

21 above the expected A1CF protein size isolated and digested with proteinase K. RNA from this isolation

22 was then reverse-transcribed (AffinityScript, Agilent) and treated with ExoSAP-IT (Affymetrix) to

23 remove excess oligonucleotides. A second DNA adapter was then ligated to the cDNA fragment 3' end

24 with high-concentration PEG8000 and DMSO. Each sample aliquot then underwent quantitative

25 polymerase chain reaction (qPCR) and PCR amplification, followed by size selection by agarose gel

26 electrophoresis. eCLIP-seq libraries were then sequenced on the Illumina HiSeq 2500. 
eCLIP-seq data processing was performed according to a detailed pipeline with custom scripts

2 previously described ${ }^{17}$. Peak-level input normalization was performed by processing non-A1CF control

3 samples identically to A1CF eCLIP samples, and the number of overlapping reads between groups were

4 counted and used to calculated fold enrichment normalized by total usable read counts. Enrichment P-

5 values were determined by the Fisher Exact Test. Irreproducible discovery rate (IDR) analysis was

6 performed by adapting the 2012 ENCODE IDR Pipeline documented at

7 https://sites.google.com/site/anshulkundaje/projects/idr(Van Nostrand, et al. in preparation). eCLIP-seq

8 data are available at https://www.ncbi.nlm.nih.gov/geo (accession number GSE117633). Sequences

9 captured within IDR peaks underwent motif enrichment using MEME Suite ${ }^{18}$.

\section{Study approval}

11 All mouse care and use procedures were approved by Penn's Institutional Animal Care and Use

12 Committees.

\section{RESULTS}

\section{$15 A 1 c f^{--}$and $A 1 c f^{\mathrm{GS} / \mathrm{GS}}$ mice have elevated fasting plasma TG levels}

16 We generated viable $A 1 c f^{/-}$and $A 1 c f^{\mathrm{GS} / \mathrm{GS}}$ mice using CRISPR-Cas9 genome editing (Figure 1A,

17 Methods). We confirmed effective knockout of Alcf mRNA expression and A1CF protein expression in

$18 \mathrm{Alcf}^{-/}$mice (Figure 1B) as well as successful introduction of the GS mutation in $A 1 c f^{\mathrm{GS} / \mathrm{GS}}$ mice (Figure

19 1A). After a 4-hour fast no significant differences in plasma TG were found (Supplemental Figure 1B).

20 Strikingly, after an overnight fast $A l c f^{-/}$and $A l c f^{\mathrm{GS} / \mathrm{GS}}$ mice of both sexes exhibited significant elevations

21 in plasma TG compared to wild-type littermates (1.8-fold and 1.6-fold, respectively; Figure 1C),

22 establishing that $A 1 c f^{\mathrm{GS} / \mathrm{GS}}$ mice recapitulate the exome-chip finding published by Liu et al. and that the

23 GS mutation leads to at least partial loss of A1CF function in the lipid context.

24 Next, we separated lipoprotein fractions of plasma pooled from male mice of each genotype

25 through fast protein liquid chromatography (FPLC) and observed that the elevations in TG content of 
$1 A l c f^{/-}$and $A l c f^{\mathrm{GS} / \mathrm{GS}}$ plasma were found in the very low-density lipoprotein (VLDL) fractions (Figure

2 1D). No significant differences in TC, high-density lipoprotein (HDL) cholesterol, non-HDL cholesterol,

3 phospholipids, and non-esterified fatty acids (NEFA) were present (Figures 1E and 1F). Although

4 elevations in plasma TG often are accompanied by increased intrahepatic lipid content, no significant

5 differences in intrahepatic TG or TC were found (Supplemental Figure 1C). After establishing that our

$6 A 1 c f^{--}$mice phenocopy $A 1 c f^{\mathrm{GS} / \mathrm{GS}}$ mice, we focused our downstream studies on $A 1 c f^{-1}$ models.

\section{A1CF deficiency causes increased VLDL-TG secretion without increased apoB synthesis}

9 To assess the physiological basis for the elevated TG seen in A1CF-deficient mice, we first evaluated

10 whether fasting $A 1 c f^{-/}$mice demonstrate increased hepatic TG secretion by measuring TG plasma

11 accumulation after blocking lipolysis with intraperitoneal Pluronic P407. Compared to wild-type mice,

$12 A 1 c f^{--}$mice exhibited $25 \%$ higher TG levels at 4 hours $(P<0.05)$ and $42 \%$ higher TG levels at 6 hours

$13(P<0.001)$ after Pluronic injection (Figure 2A), consistent with increased TG secretion from the liver in

14 the setting of A1CF deficiency. To validate this further in cell culture, we generated $A 1 c f^{-/}$McArdle-

$157777(\mathrm{McA})$ rat hepatoma cells using CRISPR-Cas9 genome editing (Supplemental Figure 2A). We

16 performed radiolabeling experiments with ${ }^{35}$ S-methionine to assess apoB-100 secretion and found that

17 compared to wild-type, A1CF deficiency resulted in a 50\% increase in apoB-100 secretion $(P<0.001)$

18 and a 30\% increase in intracellular apoB-100 accumulation $(P<0.001)$ (Figure 2B). A similar pattern

19 occurred with Alcf siRNA knockdown (Supplemental Figure 2B), indicating that increased secretion is

20 unlikely due to off-target effects of genome editing.

21 To assess whether increased apoB secretion in A1CF deficiency was due to increased apoB

22 production, we first compared intrahepatic Apob expression in $A 1 c f^{-/}$and wild-type mice and found no

23 significant differences in Apob transcript levels by qPCR (Supplemental Figure 2C). We then performed a

24 pulse chase study with puromycin and found that apoB synthesis did not differ between wild-type and 
$1 A l c f^{-1}$ McA cells (Figure 2C), indicating that increased apoB production is not the driver of increased

2 apoB secretion in A1CF deficiency.

3

4 A1CF's effect on plasma TG is not mediated through TG clearance

5 We next evaluated whether decreased clearance of TG-rich lipoproteins also contributes to the elevated

6 plasma TG phenotype. Because A1CF is not expressed in adipose or skeletal muscle (Supplemental

7 Figure 1A), we anticipated any clearance differences to be mediated through hepatic uptake. Wild-type

8 and $A l \mathrm{Cf}^{-/}$mice underwent an olive oil oral fat tolerance test, and their plasma TG levels were measured

9 after oral gavage. The $A 1 c f^{-/}$mice did not exhibit decreased TG clearance compared to wild-type

10 controls, as indicated by similar TG curves and calculated areas under the curves (Figure 2D), further

11 confirming that the primary physiological mechanism for elevated plasma TG in A1CF deficiency is due

12 to increased hepatic VLDL-TG secretion.

14 A1CF is not necessary for $A p o b$ mRNA editing and apoB-48 production

15 After establishing that A1CF modulates plasma TG levels through hepatic TG secretion, we then asked

16 whether A1CF deficiency in mice leads to significantly reduced or absent $A p o b \mathrm{C}^{6666}$ to U RNA editing to

17 favor higher B-100/B-48 that would increase measured circulating TG mass. To capture the

18 transcriptomic landscape, including RNA editing events, of A1CF deficiency, we performed RNA

19 sequencing (RNA-seq) of poly-adenylated RNA isolated from whole livers of wild-type and $A 1 c f^{/-}$mice

20 (50-75 million 100 bp paired-end reads per sample, $n=6$ mice per group). The liver was selected for

21 RNA-seq due to its important role in lipoprotein metabolism. Using RDDPred (see Methods), for each

22 RNA-seq library we quantified the proportion of $A p o b$ transcripts with $C^{6666}$ to U editing. Notably, we

23 found that $60 \%$ of transcripts from wild-type mice and $67.5 \%$ of transcripts from $A 1 \mathrm{Cf}^{--}$mice underwent

24 this editing event (Figure 3A), indicating that the presence of A1CF is not necessary for this RNA editing

25 event to occur. To confirm that apoB-48 is produced in $A 1 c f^{/-}$mice without significant shifts in B-100/B- 
148 , we performed Western blotting for apoB on plasma, whole-liver protein lysates, and small intestine

2 protein lysates derived from wild-type and $A 1 c f^{--}$mice. Densitometry showed that no significant shifts in

3 B-100/B-48 occurred in the absence of A1CF (Figures 3B and 3C). Although there appeared to be a trend

4 towards increased intrahepatic B-100/B-48, this trend was not seen with circulating apoB, confirming that

5 the plasma TG phenotype seen in A1CF deficiency is not due to changes in B-100/B-48.

eCLIP-seq identifies non- $A P O B$ RNA binding targets enriched in protein processing and

\section{8 endoplasmic reiticulum (ER) stress pathways}

9 Because increased apoB-100 secretion is not due to increased apoB-100 production or a shift in B-100/B-

1048 , we next identified which non- $A P O B$ transcripts A1CF binds in order to investigate whether these

11 binding targets form a network of genes and proteins relevant to apoB secretion. To identify A1CF's

12 direct binding targets, we performed eCLIP, a method by which A1CF was UV cross-linked to its binding

13 sites and then pulled down by immunoprecipitation, followed by sequencing to map the cross-linked

14 targets ${ }^{17}$. eCLIP was performed on HepG2 cells to identify binding targets in a human genomic context.

15 Through eCLIP, 3617 significantly enriched peaks within 1233 unique binding target genes were

16 identified for A1CF, with the majority of peaks falling within the 3' untranslated region (UTR) of a

17 transcript (Figure 4A and Supplemental Table 1). In addition, A1CF's previously discovered binding

18 motif by RNAcompete ${ }^{19}$ was validated in our experiment (Figure 4B). Gene ontology and pathway

19 analysis for A1CF's binding targets revealed that the top biological processes for these targets included

20 proteasomal protein catabolism, viral immunity, cell-substrate adhesion, and response to ER stress

21 (Figure 4C).

22 Because prior reports have demonstrated that moderate levels of ER stress increase VLDL

23 secretion $^{20,21}$, we next evaluated whether levels of ER stress differ in A1CF deficiency. By Western

24 blotting analysis, $A 1 c f^{/-}$mice have increased hepatic protein expression of ER stress markers GRP78 and

25 ATF4 compared to wild-type mice (Figure 4D). Increased GRP78 expression was recapitulated in $A 1 c f^{{ }^{\prime-}}$ 
1 McA cells (Supplemental Figure 3A). Furthermore, exacerbating pre-existing ER stress by treating $A 1 c f^{-/}$

2 McA cells with the proteasomal inhibitor MG132 led to a decrease in apoB secretion and a significant

3 drop in total protein levels compared to that seen in wild-type cells (Supplemental Figure 3B and

4 Supplemental Figure 3C), results consistent with the parabolic curve of ER-stress induced apoB-100

5 secretion $^{21}$.

\section{A1CF deficiency exerts secondary effects on mRNA expression}

8 To assess whether A1CF influences intracellular stress pathways by affecting mRNA abundance of its

9 binding targets, we examined the RNA-seq profiles of $A 1 c f^{-/}$and wild-type mice for differential

10 expression patterns. With a threshold of 1.5 -fold difference in expression at FDR-adjusted $P<0.05$, we

11 identified 218 genes that were differentially expressed in hepatic A1CF deficiency (Supplemental Table

12 2). Surprisingly, very little overlap occurred between A1CF's binding targets and genes differentially

13 expressed in A1CF deficiency (Figure 5A), indicating that (1) A1CF's effects on apoB-VLDL secretion

14 are not mediated through transcriptional abundance of its binding targets and (2) A1CF's influence on

15 differential mRNA expression is a secondary rather than primary effect. This finding was validated

16 through a complementary motif enrichment analysis ${ }^{18}$ demonstrating that the 3 ' UTR sequences of

17 differentially expressed genes were not enriched for A1CF binding sites $(P=1.0)$.

18 Furthermore, genes more highly expressed in A1CF deficiency were linked to pro-inflammatory

19 regulators such as IL1ß and TNF, while a subset of downregulated genes included targets of PPAR- $\alpha$

20 (Figure 5B). Consistent with the pro-inflammatory transcriptomic landscape of A1CF deficiency, protein

21 dot blot assays on wild-type and $A 1 c f^{/-}$liver lysates revealed relatively increased expression of pro-

22 inflammatory cytokines and injury markers such as IL-27, NGAL, and Pentraxin-3 in $A 1 c f^{/-}$livers

23 (Supplemental Figure 4A). Lipogenesis genes were not significantly upregulated in RNA-seq and real-

24 time qPCR validations (Supplemental Table 2, Supplemental Figure 4B), suggesting that increased de

25 novo lipogenesis is likely not the primary pathway by which A1CF influences plasma TG levels and 
1 supporting the possibility that other mechanisms such as moderately increased ER stress may contribute

2 to altered VLDL-apoB secretion.

4 A1CF regulates RNA splicing of genes involved in protein processing and intracellular metabolism

5 Because A1CF deficiency does not significantly alter the differential mRNA expression of its binding

6 targets, we next asked whether A1CF regulates the transcriptome by inducing changes in RNA splicing,

7 an RBP-mediated process never previously attributed to A1CF. We analyzed our RNA-seq dataset for

8 differential alternative splicing (AS) between wild-type and $A 1 c f^{--}$mouse livers using MAJIQ ${ }^{22}$ and

9 found 74 AS events occurring within 54 genes (Supplemental Table 3). We considered AS events as

10 significant if the delta percent-spliced in $(\triangle \mathrm{PSI})$ for an alternative exon was greater than $10 \%$ for a

11 predicted probability $>0.9$. We prioritized AS events with $\triangle \mathrm{PSI}>20 \%$ for reverse transcription PCR

12 (RT-PCR) using an independent set of mouse livers to validate that these splicing switches occur in the

13 absence of A1CF. RT-PCR gels validate the AS events called for Papss 2, Sec31a, and Khk, among others

14 (Figures 5C and 5E). These genes encode proteins involved in sulfation, ER protein processing, and

15 intracellular fructose metabolism, respectively ${ }^{23-26}$. To further assess A1CF's effect on splicing, we

16 transfected human $\mathrm{A} 1 \mathrm{CF}$ into the $\mathrm{HKC} 8$ cell line that does not express it constitutively and found that

17 exogenous A1CF expression alone is able to induce the Papss 2 isoform seen in wild-type mouse liver

18 (Figure 5D) even though Papss 2 mRNA is not a direct binding target of A1CF. In addition, we were able

19 to confirm by eCLIP-seq that A1CF directly binds near the alternative exons for SEC 31A and KHK in

20 HepG2 cells (Figure 5E), validating that A1CF does play a regulatory role in alternative splicing for

21 select transcripts relevant to intracellular stress and metabolism.

23 A1CF regulates non- $A p o b$ mRNA editing of a limited number of genes involved in cellular stress

24 To identify other potential roles of A1CF as an RBP, we analyzed our RNA-seq dataset for differential

25 RNA editing of genes other than Apob. To decrease the likelihood of false positives, we restricted our 
1 findings to editing events occurring in at least five out of six mice per group at a rate of greater than $25 \%$.

2 In addition, we considered only known and previously documented editing events. Consistent with our

3 splicing analysis, our RNA editing analysis identified a relatively small gene set affected by A1CF

4 deficiency. A total of nine transcripts were identified as undergoing A-to-I RNA editing in wild-type

5 livers but not in the absence of A1CF (Supplemental Table 4), including the 3' UTR of Usp45, a gene

6 encoding a protein involved in ubiquitination and essential for DNA repair (Supplemental Figure 5) ${ }^{27}$.

8 A1CF mediates effects on intracellular stress by influencing protein translation

9 Although A1CF affects several differential mRNA expression and alternative splicing events in the liver,

10 the transcripts affected by these events comprise only a small fraction of A1CF's mRNA binding targets.

11 To evaluate other possible effects of $\mathrm{A} 1 \mathrm{CF}$, we examined protein-level expression of several top binding

12 targets by P-value. By Western blot analysis, GSR, CPE, and SCD1 were less abundant at the protein

13 level in the setting of A1CF deficiency despite not being differentially expressed at the mRNA level

14 (Supplemental Table 2, Figures 6 A-C). Each of these A1CF binding targets is involved in intracellular

15 stress responses (see Discussion), suggesting that A1CF may influence translation of binding targets

16 involved in the intracellular stress response that promotes increased VLDL-apoB secretion.

\section{Discussion}

19 Large-scale human genetics studies on plasma lipids have implicated many novel genomic loci in lipid

20 metabolism. One of the strongest findings from a recently conducted exome-chip study was the

21 association between $A 1 C F$ 's low-frequency missense variant Gly398Ser (GS) and plasma TG levels.

22 However, specific mechanisms through which such effect occurs remain unknown. Here we used

23 CRISPR-generated mouse and cellular models to determine novel mechanisms by which A1CF

24 influences plasma TG. By integrating transcriptomic studies with in vivo and in vitro functional studies,

25 we (1) established that the TG-associated GS variant discovered in a large human genetics study is a loss-

26 of-function mutation ${ }^{8}$, (2) discovered a new role for A1CF as a pathway-specific regulator of RNA 
1 splicing, (3) implicated A1CF in A-to-I editing that is independent of APOBEC1, (4) provided new

2 insight that A1CF influences VLDL-TG secretion, and (5) identified A1CF's involvement in ER stress as

3 a possible mechanism for increased VLDL-TG secretion.

Because A1CF was initially discovered in the context of being an auxiliary protein in APOBEC1-

5 mediated editing of $A P O B$ mRNA $^{28}$, most studies of A1CF function involved apoB isoforms in lipid

6 metabolism, but little is known about A1CF's role in modulating plasma TG. Fossat et al. previously

7 showed that A1CF was not necessary for facilitating APOBEC1's deamination of $A P O B$ mRNA $\mathrm{C}^{6666}$ to

8 introduce the premature stop codon that leads to translation of the truncated apoB-48 isoform ${ }^{29}$. A

9 separate study has shown that Apobecl knockout mice do not exhibit a TG phenotype ${ }^{16}$. These findings

10 led us to investigate whether A1CF's effects on modulating plasma TG are independent of its canonical

11 role of facilitating $A P O B$ mRNA editing. Consistent with this, we demonstrated that B-100/B-48 ratios

12 are similar in plasma, livers, and small intestines from wild-type and $A 1 c f^{-1}$ mice, suggesting that the

13 elevated TG phenotype is present in $A 1 c f^{--}$mice regardless of apoB-48 abundance. Our mice differed

14 from humans in expressing Apobecl in the liver and hence producing hepatic apoB-48 (humans apoB-48

15 is derived from the intestines only) ${ }^{30}$. Nonetheless, we were able to recapitulate the human TG phenotype

16 with the GS mutation in mice after an extended overnight fast, at which point all chylomicrons would

17 have been cleared from systemic circulation. The near doubling of fasting plasma TG was seen in both

18 male and female $A 1 c f^{--}$and $A 1 c f^{\mathrm{GS} / \mathrm{GS}}$ mice without a commensurate decrease in HDL-C, a result that

19 focused our efforts outside of HDL biology.

To identify novel pathways relevant to A1CF's modulation of plasma TG, we performed eCLIP-

21 seq on HepG2 cells and RNA-seq on wild-type and $A 1 c f^{/-}$mouse livers, because the liver is the most

22 critical player in lipoprotein production and processing. Our decision to perform eCLIP-seq on HepG2

23 cells rather than on mouse liver was based on (1) our finding that an A1CF antibody that could undergo

24 immunoprecipitation worked most cleanly in human-derived cells and (2) the concept that relevant TG-

25 related A1CF biology would need to be conserved in both human and mouse in order to yield the similar 
1 TG phenotypes seen in the human genetics study and in our mice. In our eCLIP-seq analysis, we found

2 that the majority of A1CF's binding targets were not enriched for pathways related to TG metabolism or

3 lipogenesis, but rather to proteasomal catabolism, cell adhesion, and ER stress. This result was consistent

4 with our whole-liver RNA-seq analyses that revealed lipogenesis genes were not more highly expressed

5 in $A l c f^{-/}$livers. Additionally, $A l c f^{--}$and $A l c f^{\mathrm{GS} / \mathrm{GS}}$ mice showed no differences in circulating non-

6 esterified fatty acids or intrahepatic lipid content, which is further evidence that increased lipid

7 availability in the liver is not the driving force for the elevated TG phenotype ${ }^{31,32}$. Instead, genes more

8 highly expressed in A1CF deficiency were enriched in pro-inflammatory pathways and belonged to a

9 network regulated by cytokines such as IL1ß and TNF, suggesting that A1CF deficiency results in

10 intrahepatic stress and potentially ER stress, which has been closely linked to intracellular

11 inflammation ${ }^{33,34}$. The enrichment of A1CF's binding targets in pathways related to proteasomal

12 catabolism and ER stress, as well as the observed differential protein abundance of ER stress markers

13 GRP78 and ATF4 in A1CF deficiency, are of particular interest in the study of a TG phenotype because

14 the ER is a key organelle in VLDL assembly and secretion ${ }^{35}$. Although the role of ER stress in VLDL

15 secretion is complex, moderate levels of ER stress have been shown to result in increased VLDL

16 secretion ${ }^{20,21}$. The effect of A1CF deficiency in promoting intracellular stress is therefore consistent with

17 the observed effect on increased TG secretion in vivo and increased apoB secretion in vitro.

18 Our investigation of how A1CF interacts with RNA transcripts to influence intracellular stress

19 and subsequent changes in VLDL secretion has shed light on novel roles of A1CF as an RBP in the cell.

20 Initially we hypothesized that A1CF binds the 3' UTRs of target transcripts that are then differentially

21 expressed, as RBPs similar to A1CF in terms of sequence similarity have been found to stabilize mRNA

22 transcripts by binding to 3' UTRs ${ }^{36,37}$. However, eCLIP-seq and binding motif enrichment analysis

23 revealed that A1CF does not bind to the 3'UTR of the vast majority of genes differentially expressed in

24 A1CF deficiency, indicating that these genes were differentially expressed as secondary or compensatory

25 responses to A1CF deficiency. We then examined A1CF's potential role in non-Apob RNA editing,

26 alternative splicing, and protein translation. Although A1CF's participation in the APOBEC1 RNA- 
1 editing complex has been well defined ${ }^{10,13,38-40}$, it has never been described in the context of interacting

2 with other RNA-editing enzymes such as the ADAR family. Here we show for the first time that A1CF is

3 indeed involved in the editing of multiple transcripts other than Apob mRNA, including A-to-I RNA

4 editing. The editing of $U_{s p 45}$ is especially relevant to the TG phenotype given its role in ubiquitination ${ }^{27}$,

5 which can contribute to ER stress if dysregulated. Because this editing event occurs in a non-conserved

6 portion of the 3'UTR, more studies are needed to examine A1CF-mediated RNA editing in human

7 hepatocytes.

8 In addition to demonstrating A1CF's involvement in non-Apob editing, we present novel data that

9 A1CF contributes to the regulation of AS events. Although splicing regulators generally influence the AS

10 of hundreds to thousands of genes ${ }^{41}$, A1CF regulates the AS of a discreet set of genes that have relevance

11 to essential intracellular processes such as protein transport and sulfation. Because splicing out alternative

12 exons can change protein domains and protein folding ${ }^{42,43}$, these AS events have the potential to change

13 protein function. For example, the alternatively spliced exon in $K H K$, an A1CF binding target and

14 differentially spliced gene in A1CF deficiency, results in altered fructose binding and hence fructose

15 metabolism ${ }^{44}$. Elucidating the causal mechanisms of how differential AS in A1CF deficiency contributes

16 to ER-stress induced elevations in VLDL secretion will require further work.

17 Finally, we examined whether A1CF's RNA binding targets had differential protein expression by

18 performing Western blotting on top binding targets called by P-value in our eCLIP-seq data. Although the

19 vast majority of these targets were not differentially expressed at the mRNA level, some of the top targets

20 had different relative levels of expression at the protein level, indicating that A1CF binding somehow

21 altered the translational process and thus efficiency. Future studies to examine protein abundance of

22 A1CF's binding targets on a high throughput scale will be needed to assess this finding further.

23 In summary, our studies in mouse and cellular models established that the AlCF GS variant

24 associated with plasma TG is a loss-of-function mutation and perturbs TG metabolism through complex

25 cascades of pathways. A1CF exerts its influence on plasma TG by regulating VLDL secretion in the

26 setting of intracellular and, in particular, ER stress. As an RBP, A1CF is a novel regulator of the 
1 transcriptome that mediates intracellular stress through alternative splicing, RNA editing of genes

2 involved in stress pathways and ER function, and altering protein translation of some of its targets. With

3 its diverse functions in regulating the transcriptome, A1CF likely plays multiple roles in human lipid

4 metabolism that will require further elucidation.

\section{Author Contributions}

7 JL was responsible for conception, design, data acquisition, analysis, statistics, interpretation, and drafting

8 and revising the manuscript. KM was responsible for conception, design, and revising the manuscript.

9 DMC and XW were responsible for design, data acquisition, analysis, statistics, interpretation, and

10 revising the manuscript. EVN, IR, and GWY were responsible for data acquisition, analysis, statistics,

11 and revising the manuscript. AS was responsible for data acquisition and revising the manuscript. YB,

$12 \mathrm{BR}$, and YP were responsible for data analysis and statistics. DJR and SK were responsible for revising

13 the manuscript.

\section{Acknowledgements}

15 We acknowledge and thank Robert Bauer, Sumeet Khetarpal, and John Millar for helpful discussions.

\section{Sources of Funding}

18 These studies were supported by NIH R01DK0999571 (to KM) and by NIH K08HL135348 (to JL). EVN

19 was a Merck Fellow of the Damon Runyon Cancer Research Foundation (DRG-2172-13) and supported

20 by an NIH K99/R00 Pathway to Independence Award (K99HG009530).

\section{Disclosures}

23 GWY is a co-founder of Locana and Eclipse BioInnovations Inc. and member of the scientific advisory

24 boards of Locana, Eclipse BioInnovations Inc. and Aquinnah Pharmaceuticals. EVN is a co-founder and

25 consultant for of Eclipse BioInnovations Inc. The terms of these arrangements have been reviewed and 
approved by the University of California, San Diego in accordance with its conflict of interest policies. All

other authors declare no competing interests.

\section{References}

1. Nikpay M, Goel A, Won H-H, Hall LM, Willenborg C, Kanoni S, Saleheen D, Kyriakou T, Nelson CP, Hopewell JC, Webb TR, Zeng L, Dehghan A, Alver M, Armasu SM, Auro K, Bjonnes A, Chasman DI, Chen S, Ford I, Franceschini N, Gieger C, Grace C, Gustafsson S, Huang J, Hwang S-J, Kim YK, Kleber ME, Lau KW, Lu X, Lu Y, Lyytikäinen L-P, Mihailov E, Morrison AC, Pervjakova N, Qu L, Rose LM, Salfati E, Saxena R, Scholz M, Smith AV, Tikkanen E, Uitterlinden A, Yang X, Zhang W, Zhao W, de Andrade M, de Vries PS, van Zuydam NR, Anand SS, Bertram L, Beutner F, Dedoussis G, Frossard P, Gauguier D, Goodall AH, Gottesman O, Haber M, Han B-G, Huang J, Jalilzadeh S, Kessler T, König IR, Lannfelt L, Lieb W, Lind L, Lindgren CM, Lokki M-L, Magnusson PK, Mallick NH, Mehra N, Meitinger T, Memon F-U-R, Morris AP, Nieminen MS, Pedersen NL, Peters A, Rallidis LS, Rasheed A, Samuel M, Shah SH, Sinisalo J, Stirrups KE, Trompet S, Wang L, Zaman KS, Ardissino D, Boerwinkle E, Borecki IB, Bottinger EP, Buring JE, Chambers JC, Collins R, Cupples LA, Danesh J, Demuth I, Elosua R, Epstein SE, et al. A comprehensive 1,000 Genomes-based genome-wide association meta-analysis of coronary artery disease. Nat Genet. 2015;47:1121-1130.

2. DIAbetes Genetics Replication And Meta-analysis (DIAGRAM) Consortium, Asian Genetic Epidemiology Network Type 2 Diabetes (AGEN-T2D) Consortium, South Asian Type 2 Diabetes (SAT2D) Consortium, Mexican American Type 2 Diabetes (MAT2D) Consortium, Type 2 Diabetes Genetic Exploration by Nex-generation sequencing in muylti-Ethnic Samples (T2DGENES) Consortium, Mahajan A, Go MJ, Zhang W, Below JE, Gaulton KJ, Ferreira T, Horikoshi M, Johnson AD, Ng MCY, Prokopenko I, Saleheen D, Wang X, Zeggini E, Abecasis GR, Adair LS, Almgren P, Atalay M, Aung T, Baldassarre D, Balkau B, Bao Y, Barnett AH, Barroso I, Basit A, Been LF, Beilby J, Bell GI, Benediktsson R, Bergman RN, Boehm BO, Boerwinkle E, Bonnycastle LL, Burtt N, Cai Q, Campbell H, Carey J, Cauchi S, Caulfield M, Chan JCN, Chang L-C, Chang T-J, Chang Y-C, Charpentier G, Chen C-H, Chen H, Chen Y-T, Chia K-S, Chidambaram M, Chines PS, Cho NH, Cho YM, Chuang L-M, Collins FS, Cornelis MC, Couper DJ, Crenshaw AT, van Dam RM, Danesh J, Das D, de Faire U, Dedoussis G, Deloukas P, Dimas AS, Dina C, Doney AS, Donnelly PJ, Dorkhan M, van Duijn C, Dupuis J, Edkins S, Elliott P, Emilsson V, Erbel R, Eriksson JG, Escobedo J, Esko T, Eury E, Florez JC, Fontanillas P, Forouhi NG, Forsen T, Fox C, Fraser RM, Frayling TM, Froguel P, Frossard P, Gao Y, Gertow K, Gieger C, Gigante B, Grallert H, Grant GB, Grrop LC, et al. Genome-wide trans-ancestry meta-analysis provides insight into the genetic architecture of type 2 diabetes susceptibility. Nat Genet. 2014;46:234-244.

3. Pattaro C, Teumer A, Gorski M, Chu AY, Li M, Mijatovic V, Garnaas M, Tin A, Sorice R, Li Y, Taliun D, Olden M, Foster M, Yang Q, Chen M-H, Pers TH, Johnson AD, Ko Y-A, Fuchsberger C, Tayo B, Nalls M, Feitosa MF, Isaacs A, Dehghan A, D'Adamo P, Adeyemo A, Dieffenbach AK, Zonderman AB, Nolte IM, van der Most PJ, Wright AF, Shuldiner AR, Morrison AC, Hofman A, Smith AV, Dreisbach AW, Franke A, Uitterlinden AG, Metspalu A, Tönjes A, Lupo A, Robino A, Johansson A, Demirkan A, Kollerits B, Freedman BI, Ponte B, Oostra BA, Paulweber B, Krämer BK, Mitchell BD, Buckley BM, Peralta CA, Hayward C, Helmer C, Rotimi 
CN, Shaffer CM, Müller C, Sala C, van Duijn CM, Saint-Pierre A, Ackermann D, Shriner D, Ruggiero D, Toniolo D, Lu Y, Cusi D, Czamara D, Ellinghaus D, Siscovick DS, Ruderfer D, Gieger C, Grallert H, Rochtchina E, Atkinson EJ, Holliday EG, Boerwinkle E, Salvi E, Bottinger EP, Murgia F, Rivadeneira F, Ernst F, Kronenberg F, Hu FB, Navis GJ, Curhan GC, Ehret GB, Homuth G, Coassin S, Thun G-A, Pistis G, Gambaro G, Malerba G, Montgomery GW, Eiriksdottir G, Jacobs G, Li G, Wichmann H-E, et al. Genetic associations at 53 loci highlight cell types and biological pathways relevant for kidney function. Nat Comms. 2016;7:10023.

4. Global Lipids Genetics Consortium, Willer CJ, Schmidt EM, Sengupta S, Peloso GM, Gustafsson S, Kanoni S, Ganna A, Chen J, Buchkovich ML, Mora S, Beckmann JS, Bragg-Gresham JL, Chang H-Y, Demirkan A, Hertog Den HM, Do R, Donnelly LA, Ehret GB, Esko T, Feitosa MF, Ferreira T, Fischer K, Fontanillas P, Fraser RM, Freitag DF, Gurdasani D, Heikkilä K, Hyppönen E, Isaacs A, Jackson AU, Johansson A, Johnson T, Kaakinen M, Kettunen J, Kleber ME, Li X, Luan J, Lyytikäinen L-P, Magnusson PKE, Mangino M, Mihailov E, Montasser ME, MüllerNurasyid M, Nolte IM, O'Connell JR, Palmer CD, Perola M, Petersen A-K, Sanna S, Saxena R, Service SK, Shah S, Shungin D, Sidore C, Song C, Strawbridge RJ, Surakka I, Tanaka T, Teslovich TM, Thorleifsson G, Van den Herik EG, Voight BF, Volcik KA, Waite LL, Wong A, Wu Y, Zhang W, Absher D, Asiki G, Barroso I, Been LF, Bolton JL, Bonnycastle LL, Brambilla P, Burnett MS, Cesana G, Dimitriou M, Doney ASF, Döring A, Elliott P, Epstein SE, Eyjolfsson GI, Gigante B, Goodarzi MO, Grallert H, Gravito ML, Groves CJ, Hallmans G, Hartikainen A-L, Hayward C, Hernandez D, Hicks AA, Holm H, Hung Y-J, Illig T, Jones MR, Kaleebu P, et al. Discovery and refinement of loci associated with lipid levels. Nat Genet. 2013;45:1274-1283.

5. Morris AP, Voight BF, Teslovich TM, Ferreira T, Segrè AV, Steinthorsdottir V, Strawbridge RJ, Khan H, Grallert H, Mahajan A, Prokopenko I, Kang HM, Dina C, Esko T, Fraser RM, Kanoni S, Kumar A, Lagou V, Langenberg C, Luan J, Lindgren CM, Müller-Nurasyid M, Pechlivanis S, Rayner NW, Scott LJ, Wiltshire S, Yengo L, Kinnunen L, Rossin EJ, Raychaudhuri S, Johnson AD, Dimas AS, Loos RJF, Vedantam S, Chen H, Florez JC, Fox C, Liu C-T, Rybin D, Couper DJ, Kao WHL, Li M, Cornelis MC, Kraft P, Sun Q, van Dam RM, Stringham HM, Chines PS, Fischer K, Fontanillas P, Holmen OL, Hunt SE, Jackson AU, Kong A, Lawrence R, Meyer J, Perry JRB, Platou CGP, Potter S, Rehnberg E, Robertson N, Sivapalaratnam S, Stancáková A, Stirrups K, Thorleifsson G, Tikkanen E, Wood AR, Almgren P, Atalay M, Benediktsson R, Bonnycastle LL, Burtt N, Carey J, Charpentier G, Crenshaw AT, Doney ASF, Dorkhan M, Edkins S, Emilsson V, Eury E, Forsen T, Gertow K, Gigante B, Grant GB, Groves CJ, Guiducci C, Herder C, Hreidarsson AB, Hui J, James A, Jonsson A, Rathmann W, Klopp N, Kravic J, Krjutškov K, Langford C, Leander K, Lindholm E, et al. Large-scale association analysis provides insights into the genetic architecture and pathophysiology of type 2 diabetes. Nat Genet. 2012;44:981-990.

6. Do R, Stitziel NO, Won H-H, Jørgensen AB, Duga S, Angelica Merlini P, Kiezun A, Farrall M, Goel A, Zuk O, Guella I, Asselta R, Lange LA, Peloso GM, Auer PL, NHLBI Exome Sequencing Project, Girelli D, Martinelli N, Farlow DN, DePristo MA, Roberts R, Stewart AFR, Saleheen D, Danesh J, Epstein SE, Sivapalaratnam S, Kees Hovingh G, Kastelein JJ, Samani NJ, Schunkert H, Erdmann J, Shah SH, Kraus WE, Davies R, Nikpay M, Johansen CT, Wang J, Hegele RA, Hechter E, März W, Kleber ME, Huang J, Johnson AD, Li M, Burke GL, Gross M, Liu Y, Assimes TL, Heiss G, Lange EM, Folsom AR, Taylor HA, Olivieri O, Hamsten A, Clarke R, Reilly DF, Yin W, Rivas MA, Donnelly P, Rossouw JE, Psaty BM, Herrington DM, Wilson JG, Rich SS, Bamshad MJ, Tracy RP, Adrienne Cupples L, Rader DJ, Reilly MP, Spertus JA, Cresci S, Hartiala J, Wilson Tang WH, Hazen SL, Allayee H, Reiner AP, Carlson CS, Kooperberg C, Jackson RD, Boerwinkle E, Lander ES, Schwartz SM, Siscovick DS, McPherson R, TybjaergHansen A, Abecasis GR, Watkins H, Nickerson DA, Ardissino D, Sunyaev SR, O'Donnell CJ, 
Altshuler D, Gabriel S, Kathiresan S. Exome sequencing identifies rare LDLR and APOA5 alleles conferring risk for myocardial infarction. Nature. 2014;

7. CARDIoGRAMplusC4D Consortium, Deloukas P, Kanoni S, Willenborg C, Farrall M, Assimes TL, Thompson JR, Ingelsson E, Saleheen D, Erdmann J, Goldstein BA, Stirrups K, König IR, Cazier J-B, Johansson A, Hall AS, Lee J-Y, Willer CJ, Chambers JC, Esko T, Folkersen L, Goel A, Grundberg E, Havulinna AS, Ho WK, Hopewell JC, Eriksson N, Kleber ME, Kristiansson K, Lundmark P, Lyytikäinen L-P, Rafelt S, Shungin D, Strawbridge RJ, Thorleifsson G, Tikkanen E, Van Zuydam N, Voight BF, Waite LL, Zhang W, Ziegler A, Absher D, Altshuler D, Balmforth AJ, Barroso I, Braund PS, Burgdorf C, Claudi-Boehm S, Cox D, Dimitriou M, Do R, DIAGRAM Consortium, CARDIOGENICS Consortium, Doney ASF, Mokhtari El N, Eriksson P, Fischer K, Fontanillas P, Franco-Cereceda A, Gigante B, Groop L, Gustafsson S, Hager J, Hallmans G, Han B-G, Hunt SE, Kang HM, Illig T, Kessler T, Knowles JW, Kolovou G, Kuusisto J, Langenberg C, Langford C, Leander K, Lokki M-L, Lundmark A, McCarthy MI, Meisinger C, Melander O, Mihailov E, Maouche S, Morris AD, Müller-Nurasyid M, MuTHER Consortium, Nikus K, Peden JF, Rayner NW, Rasheed A, Rosinger S, Rubin D, Rumpf MP, Schäfer A, Sivananthan M, Song C, Stewart AFR, Tan S-T, Thorgeirsson G, et al. Large-scale association analysis identifies new risk loci for coronary artery disease. Nat Genet. 2013;45:25-33.

8. Liu DJ, Peloso GM, Yu H, Butterworth AS, Wang X, Mahajan A, Saleheen D, Emdin C, Alam D, Alves AC, Amouyel P, Di Angelantonio E, Arveiler D, Assimes TL, Auer PL, Baber U, Ballantyne CM, Bang LE, Benn M, Bis JC, Boehnke M, Boerwinkle E, Bork-Jensen J, Bottinger EP, Brandslund I, Brown M, Busonero F, Caulfield MJ, Chambers JC, Chasman DI, Chen YE, Chen Y-DI, Chowdhury R, Christensen C, Chu AY, Connell JM, Cucca F, Cupples LA, Damrauer SM, Davies G, Deary IJ, Dedoussis G, Denny JC, Dominiczak A, Dubé M-P, Ebeling T, Eiriksdottir G, Esko T, Farmaki A-E, Feitosa MF, Ferrario M, Ferrières J, Ford I, Fornage M, Franks PW, Frayling TM, Frikke-Schmidt R, Fritsche LG, Frossard P, Fuster V, Ganesh SK, Gao W, Garcia ME, Gieger C, Giulianini F, Goodarzi MO, Grallert H, Grarup N, Groop L, Grove ML, Gudnason V, Hansen T, Harris TB, Hayward C, Hirschhorn JN, Holmen OL, Huffman J, Huo Y, Hveem K, Jabeen S, Jackson AU, Jakobsdottir J, Järvelin M-R, Jensen GB, Jørgensen ME, Jukema JW, Justesen JM, Kamstrup PR, Kanoni S, Karpe F, Kee F, Khera AV, Klarin D, Koistinen HA, Kooner JS, Kooperberg C, Kuulasmaa K, Kuusisto J, et al. Exome-wide association study of plasma lipids in >300,000 individuals. Nat Genet. 2017;49:1758-1766.

9. Mehta A, Kinter MT, Sherman NE, Driscoll DM. Molecular cloning of apobec-1 complementation factor, a novel RNA-binding protein involved in the editing of apolipoprotein B mRNA. Molecular and Cellular Biology. 2000;20:1846-1854.

10. Chester A, Weinreb V, Carter CW, Navaratnam N. Optimization of apolipoprotein B mRNA editing by APOBEC1 apoenzyme and the role of its auxiliary factor, ACF. RNA. 2004;10:13991411.

11. Teng BB, Ochsner S, Zhang Q, Soman KV, Lau PP, Chan L. Mutational analysis of apolipoprotein B mRNA editing enzyme (APOBEC1). structure-function relationships of RNA editing and dimerization. The Journal of Lipid Research. 1999;40:623-635. 
13. Lehmann DM, Galloway CA, MacElrevey C, Sowden MP, Wedekind JE, Smith HC. Functional characterization of APOBEC-1 complementation factor phosphorylation sites. Biochim Biophys Acta. 2007;1773:408-418.

14. Galloway CA, Kumar A, Krucinska J, Smith HC. APOBEC-1 complementation factor (ACF) forms RNA-dependent multimers. Biochem Biophys Res Commun. 2010;398:38-43.

15. Blanc V, Xie Y, Luo J, Kennedy S, Davidson NO. Intestine-specific expression of Apobec-1 rescues apolipoprotein B RNA editing and alters chylomicron production in Apobec1-/- mice. The Journal of Lipid Research. 2012;53:2643-2655.

16. Nakamuta M, Chang BH, Zsigmond E, Kobayashi K, Lei H, Ishida BY, Oka K, Li E, Chan L. Complete phenotypic characterization of apobec-1 knockout mice with a wild-type genetic background and a human apolipoprotein B transgenic background, and restoration of apolipoprotein B mRNA editing by somatic gene transfer of Apobec-1. J Biol Chem. 1996;271:25981-25988.

17. Van Nostrand EL, Pratt GA, Shishkin AA, Gelboin-Burkhart C, Fang MY, Sundararaman B, Blue SM, Nguyen TB, Surka C, Elkins K, Stanton R, Rigo F, Guttman M, Yeo GW. Robust transcriptome-wide discovery of RNA-binding protein binding sites with enhanced CLIP (eCLIP). Nat Meth. 2016;13:508-514.

18. Bailey TL, Boden M, Buske FA, Frith M, Grant CE, Clementi L, Ren J, Li WW, Noble WS. MEME SUITE: tools for motif discovery and searching. Nucleic Acids Research. 2009;37:W202W208.

19. Ray D, Kazan H, Cook KB, Weirauch MT, Najafabadi HS, Li X, Gueroussov S, Albu M, Zheng H, Yang A, Na H, Irimia M, Matzat LH, Dale RK, Smith SA, Yarosh CA, Kelly SM, Nabet B, Mecenas D, Li W, Laishram RS, Qiao M, Lipshitz HD, Piano F, Corbett AH, Carstens RP, Frey BJ, Anderson RA, Lynch KW, Penalva LOF, Lei EP, Fraser AG, Blencowe BJ, Morris QD, Hughes TR. A compendium of RNA-binding motifs for decoding gene regulation. Nature. 2013;499:172-177.

20. Ai D, Baez JM, Jiang H, Conlon DM, Hernandez-Ono A, Frank-Kamenetsky M, Milstein S, Fitzgerald K, Murphy AJ, Woo CW, Strong A, Ginsberg HN, Tabas I, Rader DJ, Tall AR. Activation of ER stress and mTORC1 suppresses hepatic sortilin-1 levels in obese mice. J Clin Invest. 2012;122:1677-1687.

21. Ota T, Gayet C, Ginsberg HN. Inhibition of apolipoprotein B100 secretion by lipid-induced hepatic endoplasmic reticulum stress in rodents. J Clin Invest. 2008;118:316-332.

22. Vaquero-Garcia J, Barrera A, Gazzara MR, González-Vallinas J, Lahens NF, Hogenesch JB, Lynch KW, Barash Y. A new view of transcriptome complexity and regulation through the lens of local splicing variations. eLife. 2016;5:e11752.

23. Coricor G, Serra R. TGF- $\beta$ regulates phosphorylation and stabilization of Sox 9 protein in chondrocytes through p38 and Smad dependent mechanisms. Sci Rep. 2016;:1-11.

24. Wang Y, Liu L, Zhang H, Fan J, Zhang F, Yu M, Shi L, Yang L, Lam SM, Wang H, Chen X, Wang Y, Gao F, Shui G, Xu Z. Mea6 controls VLDL transport through the coordinated regulation of COPII assembly. Cell Research. 2016;26:787-804. 
25. Martherus RSRM, Sluiter W, Timmer EDJ, VanHerle SJV, Smeets HJM, Ayoubi TAY. Functional annotation of heart enriched mitochondrial genes GBAS and CHCHD10 through guilt by association. Biochem Biophys Res Commun. 2010;402:203-208.

26. Kansaku A, Hirabayashi S, Mori H, Fujiwara N, Kawata A, Ikeda M, Rokukawa C, Kurihara H, Hata Y. Ligand-of-Numb protein X is an endocytic scaffold for junctional adhesion molecule 4. Oncogene. 2006;84:165-14.

27. Perez-Oliva AB, Lachaud C, Szyniarowski P, Muñoz I, Macartney T, Hickson I, Rouse J, Alessi DR. USP45 deubiquitylase controls ERCC1-XPF endonuclease-mediated DNA damage responses. The EMBO Journal. 2015;34:326-343.

28. Lellek H, Kirsten R, Diehl I, Apostel F, Buck F, Greeve J. Purification and molecular cloning of a novel essential component of the apolipoprotein B mRNA editing enzyme-complex. J Biol Chem. 2000;275:19848-19856.

13 29. Fossat N, Tourle K, Radziewic T, Barratt K, Liebhold D, Studdert JB, Power M, Jones V, Loebel DAF, Tam PPL. C to U RNA editing mediated by APOBEC1 requires RNA-binding protein RBM47. EMBO reports. 2014;15:903-910.

30. Zheng C. Metabolism of apoB lipoproteins of intestinal and hepatic origin during constant feeding of small amounts of fat. The Journal of Lipid Research. 2006;47:1771-1779.

31. Vatner DF, Majumdar SK, Kumashiro N, Petersen MC, Rahimi Y, Gattu AK, Bears M, Camporez J-PG, Cline GW, Jurczak MJ, Samuel VT, Shulman GI. Insulin-independent regulation of hepatic triglyceride synthesis by fatty acids. Proc Natl Acad Sci USA. 2015;112:1143-1148.

32. Bauer RC, Sasaki M, Cohen DM, Cui J, Smith MA, Yenilmez BO, Steger DJ, Rader DJ. Tribbles1 regulates hepatic lipogenesis through posttranscriptional regulation of $\mathrm{C} / \mathrm{EBP} \alpha$. J Clin Invest. 2015;125:3809-3818.

33. Endoplasmic Reticulum Stress Interacts With Inflammation in Human Diseases. J Cell Physiol. 2015;231:288-294.

34. Chaudhari N, Talwar P, Parimisetty A, Lefebvre d'Hellencourt C, Ravanan P. A molecular web: endoplasmic reticulum stress, inflammation, and oxidative stress. Front Cell Neurosci. 2014;8:213.

35. Yamaguchi J, Gamble MV, Conlon D, Liang J-S, Ginsberg HN. The conversion of apoB100 low density lipoprotein/high density lipoprotein particles to apoB100 very low density lipoproteins in response to oleic acid occurs in the endoplasmic reticulum and not in the Golgi in McA RH7777 cells. J Biol Chem. 2003;278:42643-42651.

36. Chang X, Li B, Rao A. RNA-binding protein hnRNPLL regulates mRNA splicing and stability during B-cell to plasma-cell differentiation. Proceedings of the National Academy of Sciences. 2015;112:E1888-E1897.

36 37. Carpenter S, Ricci EP, Mercier BC, Moore MJ, Fitzgerald KA. Post-transcriptional regulation of 
1 38. Blanc V, Kennedy S, Davidson NO. A novel nuclear localization signal in the auxiliary domain of apobec-1 complementation factor regulates nucleocytoplasmic import and shuttling. J Biol Chem. 2003;278:41198-41204.

4 39. Blanc V, Henderson JO, Kennedy S, Davidson NO. Mutagenesis of apobec-1 complementation factor reveals distinct domains that modulate RNA binding, protein-protein interaction with apobec-1, and complementation of C to U RNA-editing activity. J Biol Chem. 2001;276:4638646393.

40. Chester A, Somasekaram A, Tzimina M, Jarmuz A, Gisbourne J, O'Keefe R, Scott J, Navaratnam $\mathrm{N}$. The apolipoprotein B mRNA editing complex performs a multifunctional cycle and suppresses nonsense-mediated decay. The EMBO Journal. 2003;22:3971-3982.

11 41. Ip JY, Tong A, Pan Q, Topp JD, Blencowe BJ, Lynch KW. Global analysis of alternative splicing during T-cell activation. RNA. 2007;13:563-572.

13 42. Ellis JD, Barrios-Rodiles M, Çolak R, Irimia M, Kim T, Calarco JA, Wang X, Pan Q, O'Hanlon D,

Kim PM, Wrana JL, Blencowe BJ. Tissue-specific alternative splicing remodels protein-protein interaction networks. Mol Cell. 2012;46:884-892.

43. Irimia M, Weatheritt RJ, Ellis JD, Parikshak NN, Gonatopoulos-Pournatzis T, Babor M, QuesnelVallières M, Tapial J, Raj B, O'Hanlon D, Barrios-Rodiles M, Sternberg MJE, Cordes SP, Roth FP, Wrana JL, Geschwind DH, Blencowe BJ. A Highly Conserved Program of Neuronal Microexons Is Misregulated in Autistic Brains. Cell. 2014;159:1511-1523.

44. Ishimoto T, Lanaspa MA, Le MT, Garcia GE, Diggle CP, Maclean PS, Jackman MR, Asipu A, Roncal-Jimenez CA, Kosugi T, Rivard CJ, Maruyama S, Rodriguez-Iturbe B, Sánchez-Lozada LG, Bonthron DT, Sautin YY, Johnson RJ. Opposing effects of fructokinase C and A isoforms on fructose-induced metabolic syndrome in mice. Proceedings of the National Academy of Sciences. 2012;109:4320-4325. 
A

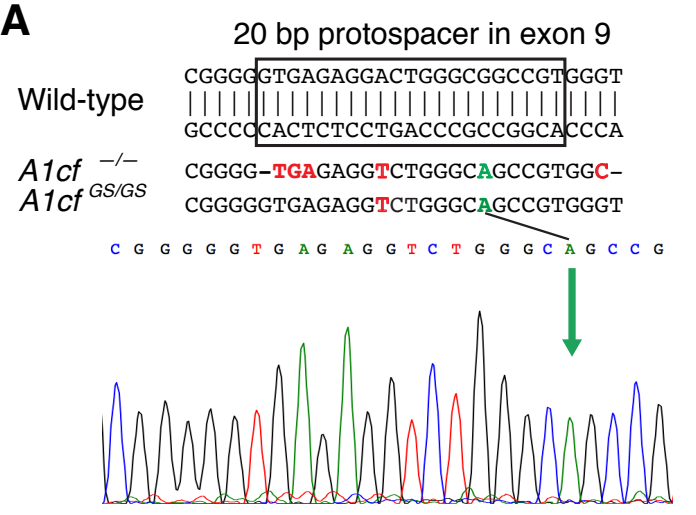

C

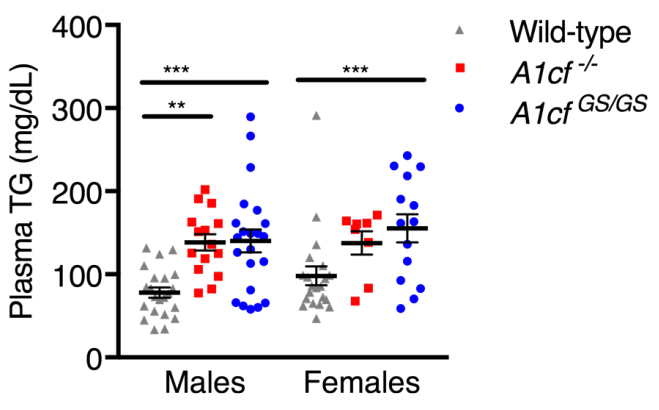

E

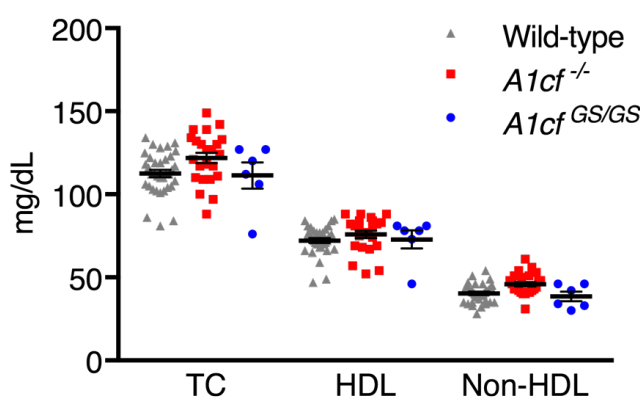

B $65 \mathrm{kDa}$ Wild-type $A_{1 f^{-/-}}$A1cf ${ }^{\text {GS/GS }}$ -1 WB: A1CF
$\square$ WB: B-actin

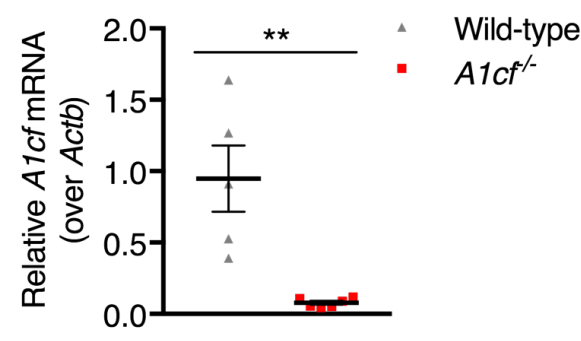

D

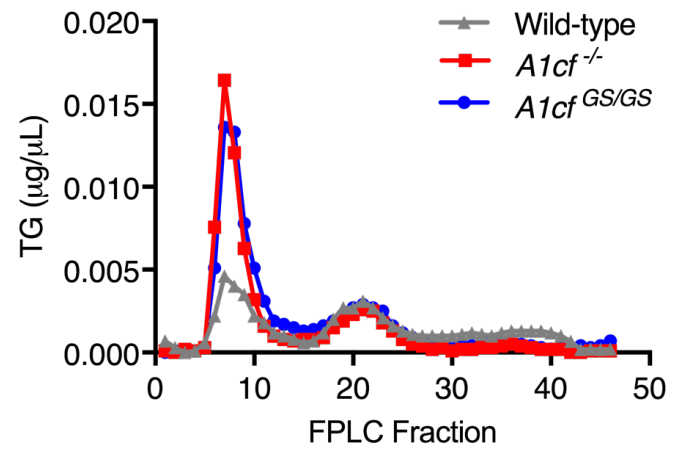

$\mathbf{F}$

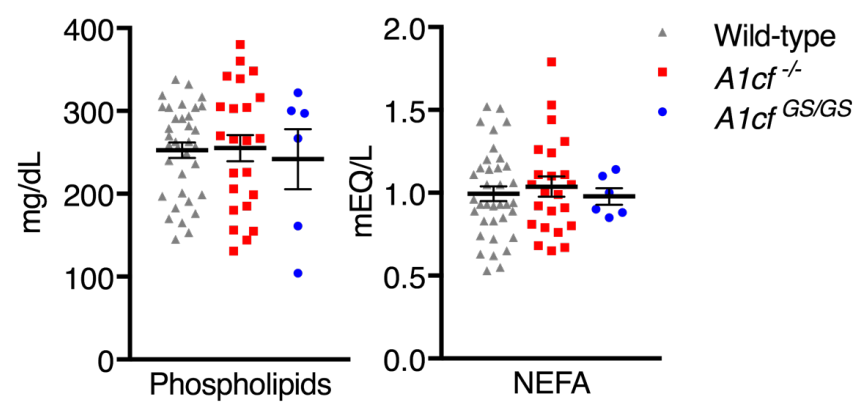

Figure 1. $A 1 c f^{/-}$and $A 1 c f^{\mathrm{GS} / \mathrm{GS}}$ mice have elevated fasting plasma TG levels. (A) $A 1 c f^{-/}$and $A 1 c f^{\mathrm{GS} / \mathrm{GS}}$ mice were generated using CRISPR-Cas9 genome editing. The protospacer and PAM within exon 9 of Alcf are demarcated for the wild-type sequence. Deletion of one bp induces a frameshift and premature stop codon (red) in one of the founder mice. Sanger sequencing confirms knock-in of the GS mutation (green). (B) Whole-liver protein lysates were separated by SDS-page and immunoblotted for A1CF. Representative blot shown includes $n=3$ per group. RNA was also isolated from mouse livers and assayed for $A l c f$ expression via real-time quantitative PCR, ** $P<0.01$ ( $n=6$ mice per group). (C) Plasma TG of male and female wild-type $(n=21-22), A 1 c f^{/-}(n=8-15)$, and $A 1 c f^{\mathrm{GS} / \mathrm{GS}}$ mice $(n=14-22)$ were measured after an overnight fast. $* * P<0.01$, *** $P<0.001$. (D) Pooled plasma samples from mice of each genotype were fractionated by size, and TG content for each fraction was measured by fast protein liquid chromatography (FPLC). (E) Total cholesterol (TC), high-density lipoprotein (HDL), and non-HDL cholesterol levels were measured in wild-type $(n=36), A 1 c f^{/-}(n=22)$, and $A 1 c f^{\mathrm{GS} / \mathrm{GS}}(n=6)$ mice after an overnight fast. (F) Phospholipids and non-esterified fatty acids (NEFA) were measured in wild-type $(n=36), A 1 c f^{--}(n=22)$, and $A 1 c f^{\mathrm{GS} / \mathrm{GS}}(n=6)$ mice after an overnight fast. 

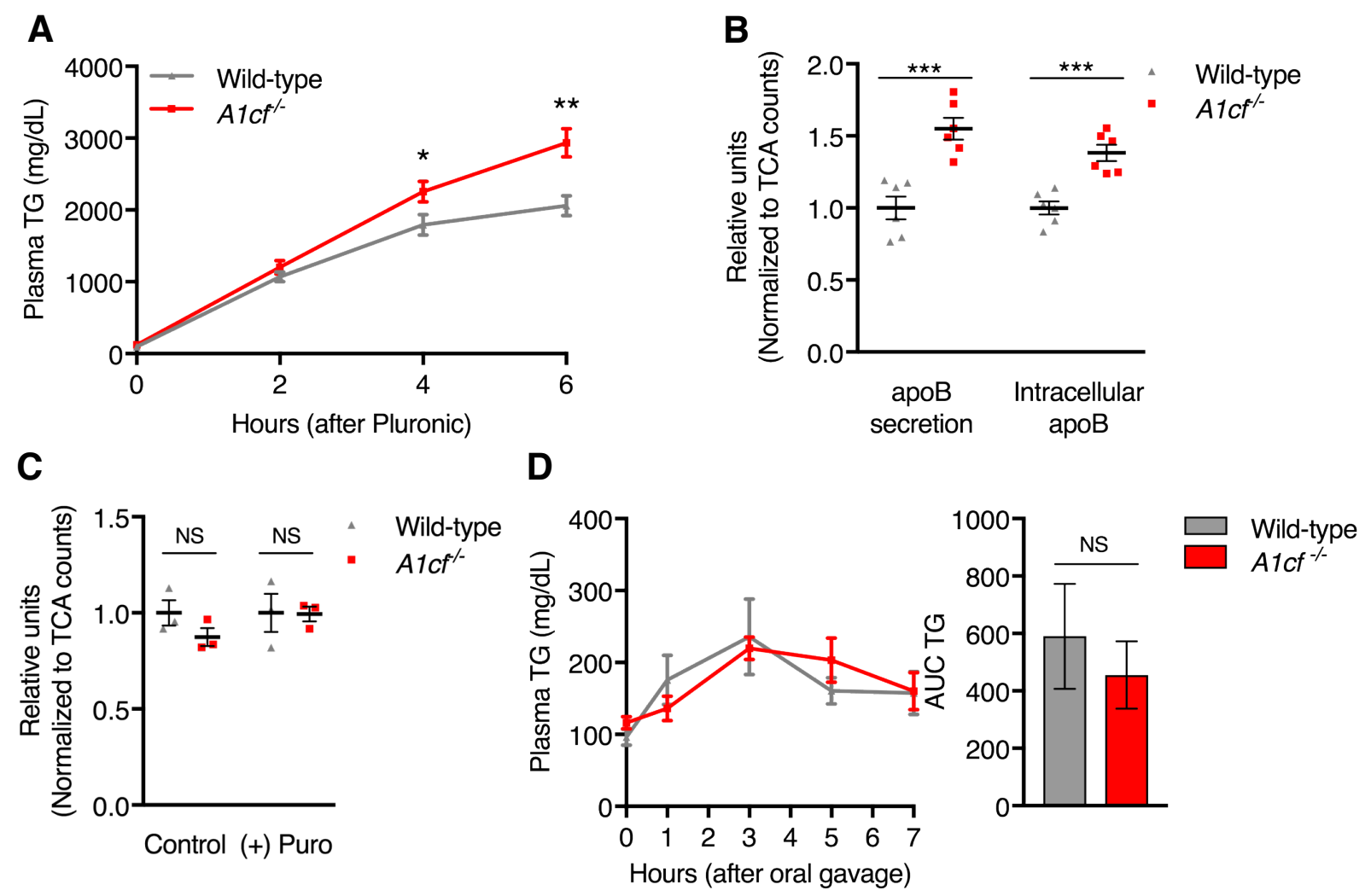

Figure 2. A1CF deficiency causes increased VLDL-TG secretion but does not decrease TG

clearance. (A) Mice were injected i.p. with Pluronic P407 after an overnight fast. Plasma TG levels were measured after injection. ${ }^{*} P<0.05, * * P<0.01$ ( $n=4-5$ mice per group). Results representative of 3 experiments. (B) $A 1 \mathrm{cf}^{-1}$ rat hepatoma McArdle (McA) cells were generated using CRISPR-Cas9 genome editing. Cultured knockout and wild-type McA cells underwent radiolabeling with ${ }^{35} \mathrm{~S}-$ methionine/cysteine, and newly synthesized cellular and secreted labeled apoB were measured. *** $P<$ 0.001 ( $n=6$ wells per group). (C) McA cells were treated with and without $10 \mathrm{uM}$ puromycin followed

9 by pulse radiolabeling with ${ }^{35} \mathrm{~S}-$ methionine/cysteine to assess differences in apoB synthesis. Data

10 represent relative amounts of intracellular radiolabeled apoB. (D) Mice were subjected to olive oil gavage after an overnight fast, and their plasma TG levels were measured after gavage. Clearance was assessed by AUC. ( $n=4-5$ mice per group). Results representative of 2 experiments. 
A

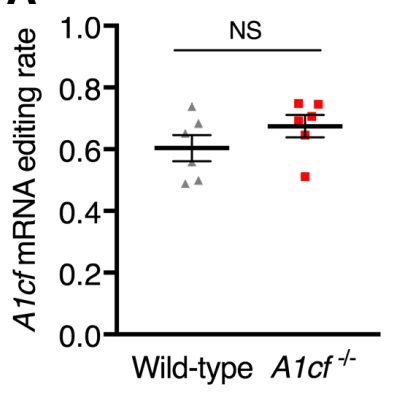

B

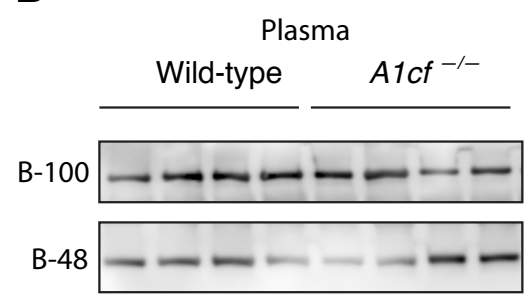

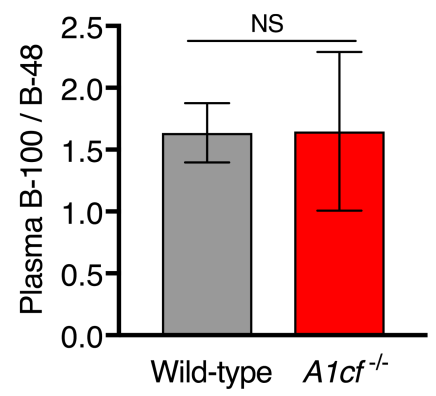

C
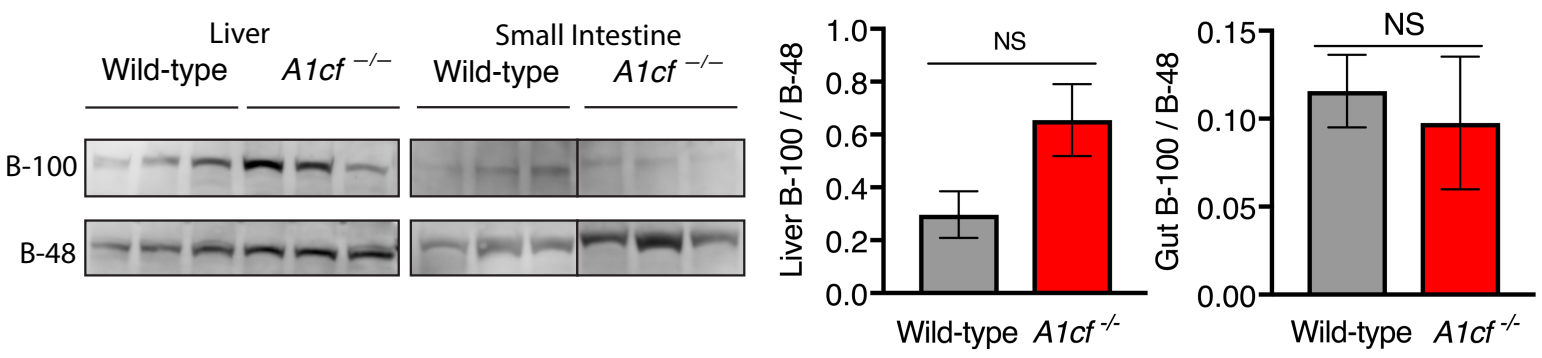

Figure 3. A1CF is not necessary for apoB-48 production through Apob mRNA editing. (A) RNAediting rate for $\mathrm{C}^{6666} A p o b$ mRNA of wild-type and $A 1 C f^{-/}$livers was calculated from RNA-seq using RDDPred (see Methods). $n=6$ mice per group. (B) Plasma proteins from wild-type and $A 1 c f^{-/}$mice were separated by SDS-page and immunoblotted for apoB ( $n=5$ mice per group). Densitometry of the blot is reported as apoB-100/apoB-48 ratios and was analyzed with Student's $t$-test. (C) Whole-liver and partial small-intestine protein lysates were separated by SDS-page and immunoblotted for apoB $(n=6$ per group). Densitometry of the blot is reported as apoB-100/apoB-48 ratios and was analyzed with Student's $t$-test. 
A

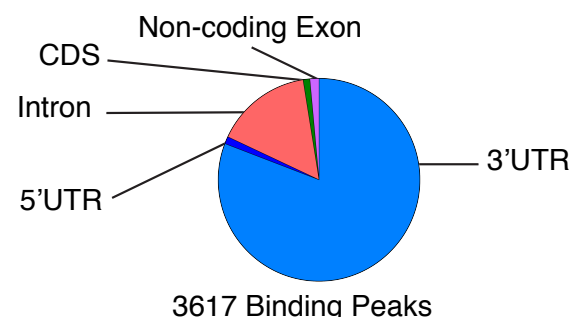

C

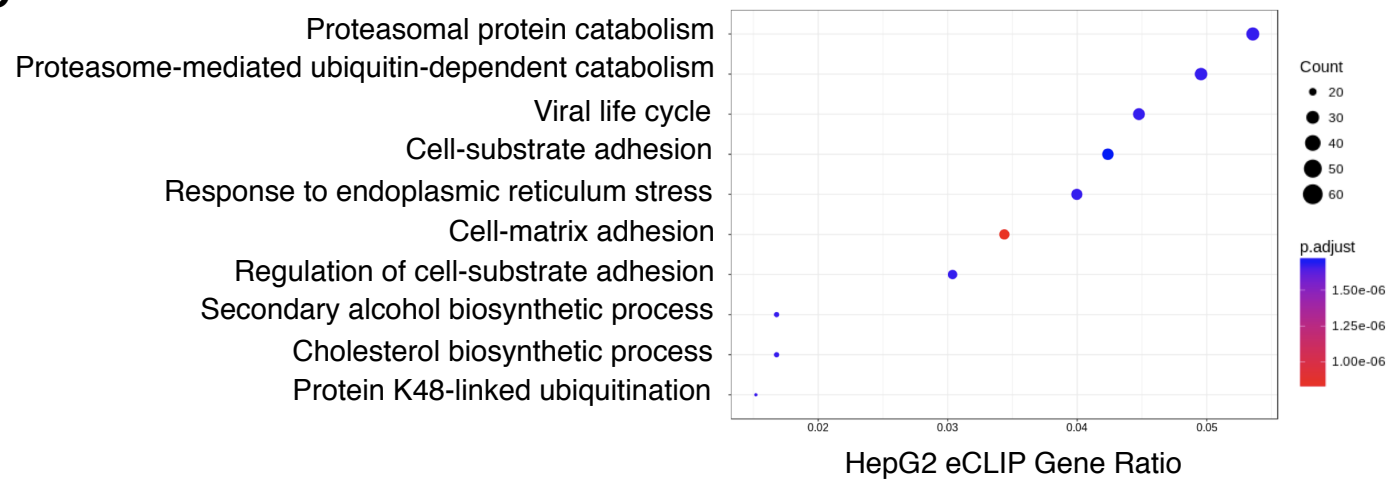

D

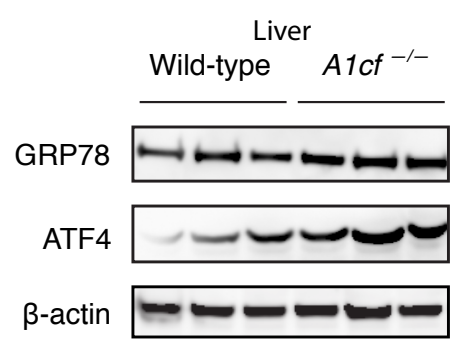

B

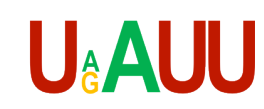

Binding Motif Enrichment: $2.4 \times 10^{-4}$

2 Figure 4. Enhanced CLIP-seq identifies A1CF's binding targets. Enhanced CLIP-seq (eCLIP) was performed on HepG2 cells to identify A1CF's RNA binding targets. (A) eCLIP identified 1411 binding clusters, and the distribution of these clusters among gene regions is represented in the chart. The vast majority of binding clusters fall within the 3'UTR of a gene. (B) Sequences from the binding clusters underwent motif enrichment analysis, which confirmed the predominant binding motif on eCLIP is consistent with the canonical binding motif. (C) Gene ontology analysis for genes represented in eCLIP binding clusters (eCLIP genes). The gene ratio reflects the relative percentage of eCLIP Genes involved in a given biological process. Top processes identified include those related to proteasomal catabolism and ER stress. (D) Whole-liver protein lysates were separated by SDS-page and immunoblotted for markers of ER stress, including GRP78 and ATF4. Blot representative of $n=6$ per group. Densitometry of the blot was analyzed with Student's $t$-test. 
A

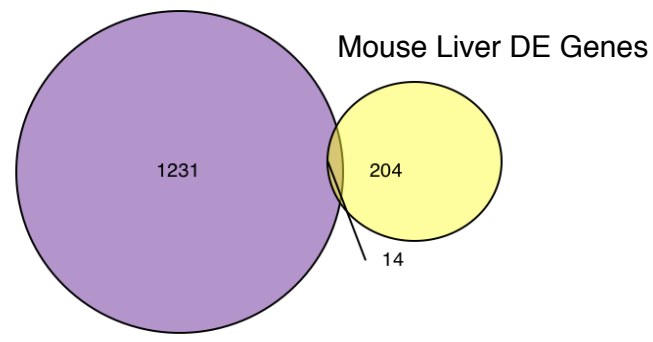

HepG2 eCLIP Genes

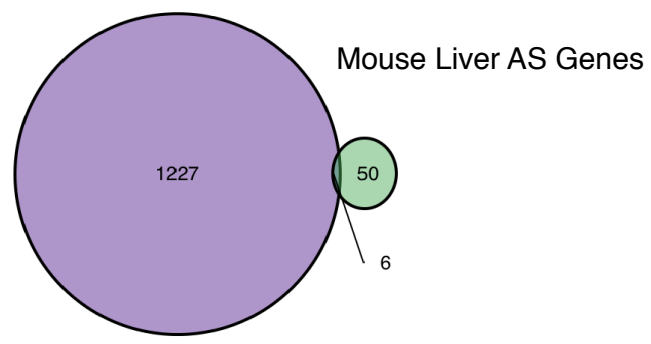

HepG2 eCLIP Genes

C

Liver Papss2 Cassette Exon Event

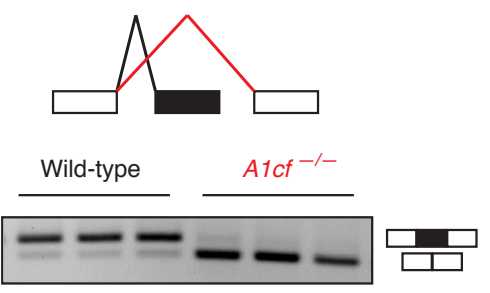

E

SEC31A Alternative Exon

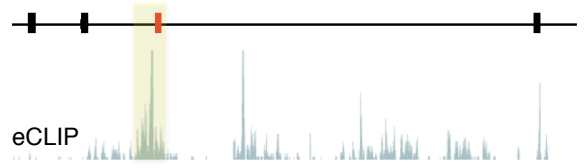

KHK Alternative Exons

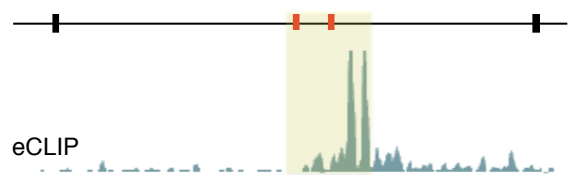

B
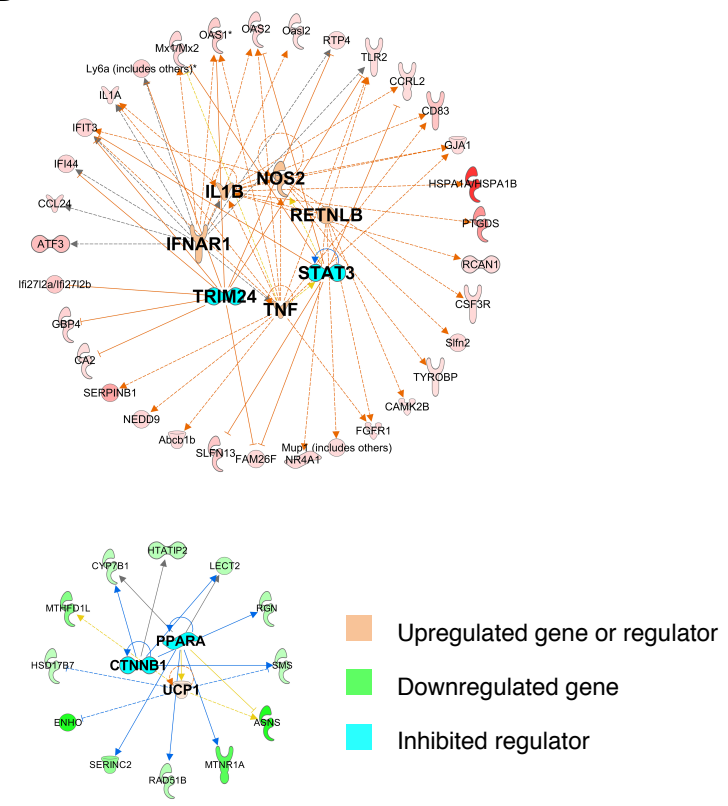

D

PAPSS2 transfected into HKC8 cells

Control Cells $\quad(+) A 1 C F$

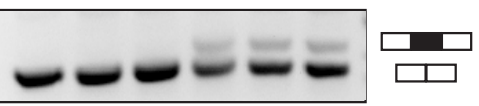

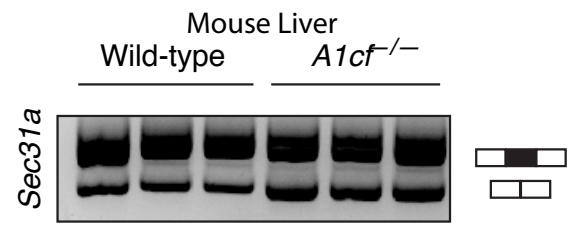

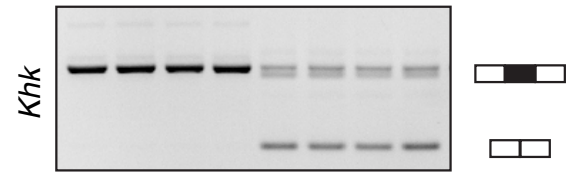

2 Figure 5. A1CF's effects on the transcriptome. (A) Venn diagrams of overlap between eCLIP genes

3 and genes differentially expressed in livers of wild-type vs. $A l \mathrm{Cf}^{-/}$mice (top) and between eCLIP genes

4 and genes differentially alternatively spliced in livers of wild-type vs. $A 1 \mathrm{cf} \mathrm{f}^{-1 /}$ mice (bottom). (B)

5 Upstream regulators of upregulated genes (top) and downregulated genes (bottom) are shown in their 
1 network relationship with their respective differentially expressed genes. (C) RNA-seq data generated for 2 wild-type and $A l c f^{-1}$ mouse livers were analyzed for differential alternative splicing (AS) events using 3 MAJIQ. MAJIQ/VOILA output for differentially spliced gene Papss 2 is shown on the right, with delta 4 percent spliced in ( $\triangle \mathrm{PSI})$ at $86.2 \%$. The black lines correspond to exon inclusion whereas the red lines 5 correspond to exon exclusion seen in A1CF deficiency. The called splicing event was validated by RT6 PCR of RNA derived from independent wild-type and $A 1 c f^{-1}$ mouse livers that were not sequenced.

7 (D)The same PAPSS2 splicing event was induced in a human cell line (HKC8) that does not express $8 A I C F$ through transfection with an $A I C F$ expression vector; RT-PCR validation shown. (E) Out of the 6 9 genes that are both alternatively spliced in A1CF deficiency and eCLIP binding targets, only SEC31A and $10 K H K$ demonstrated A1CF binding near the alternative exon. On the left for each gene, visualized eCLIP 11 reads are presented in green, with the alternatively spliced exon(s) presented in red. On the right, RT-PCR 12 validations are shown of homologous Sec31a and Khk differential AS events in wild-type and Alcf $f^{--}$ 13 mouse livers that were not sequenced. 
A
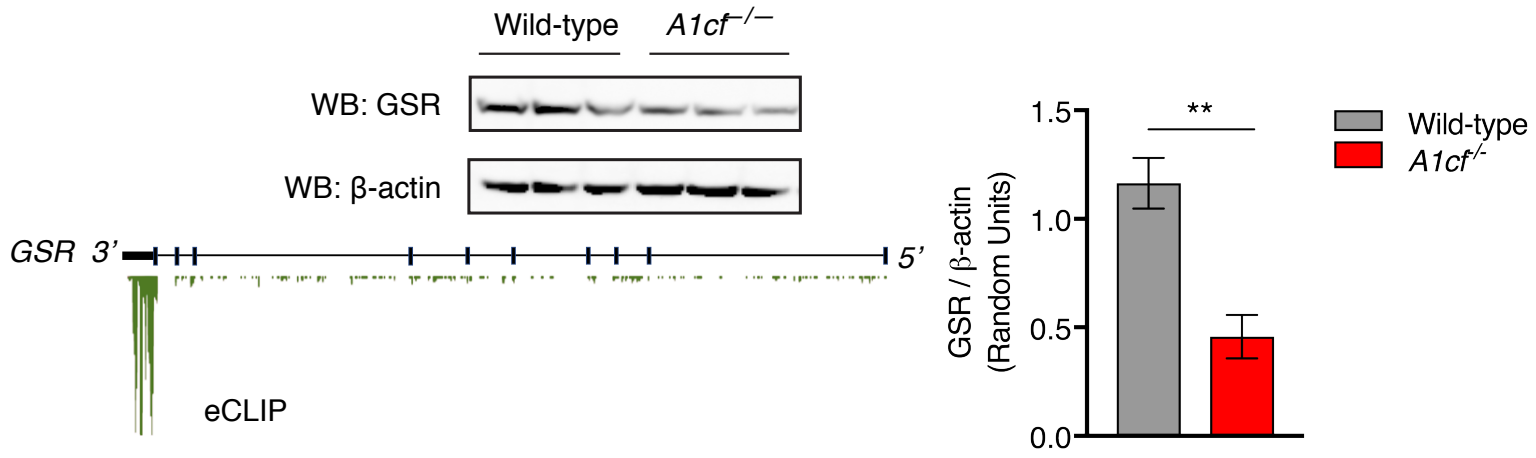

B

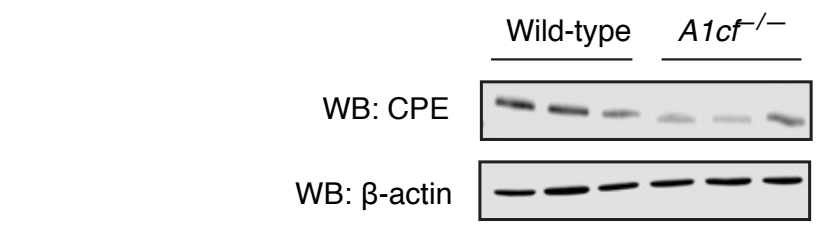

CPE 5
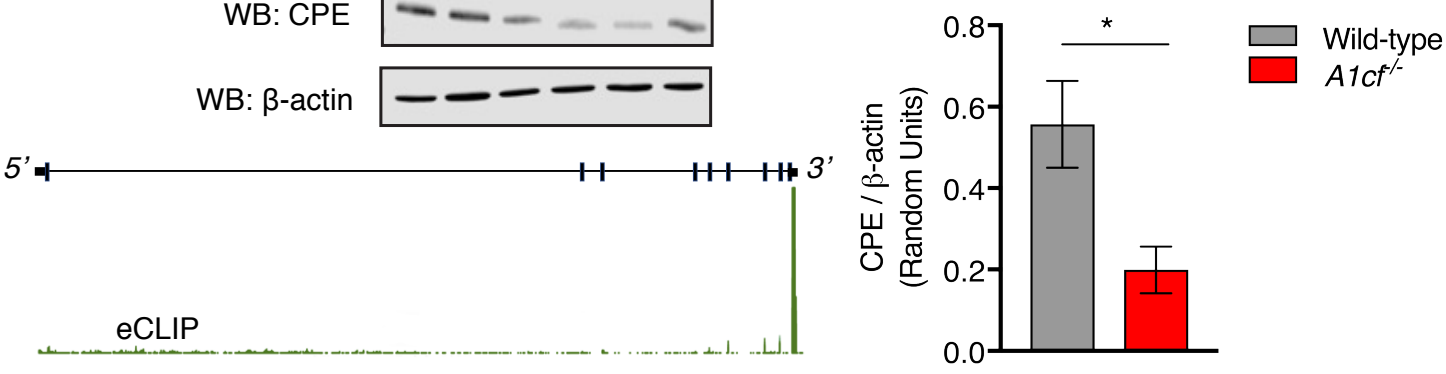

C

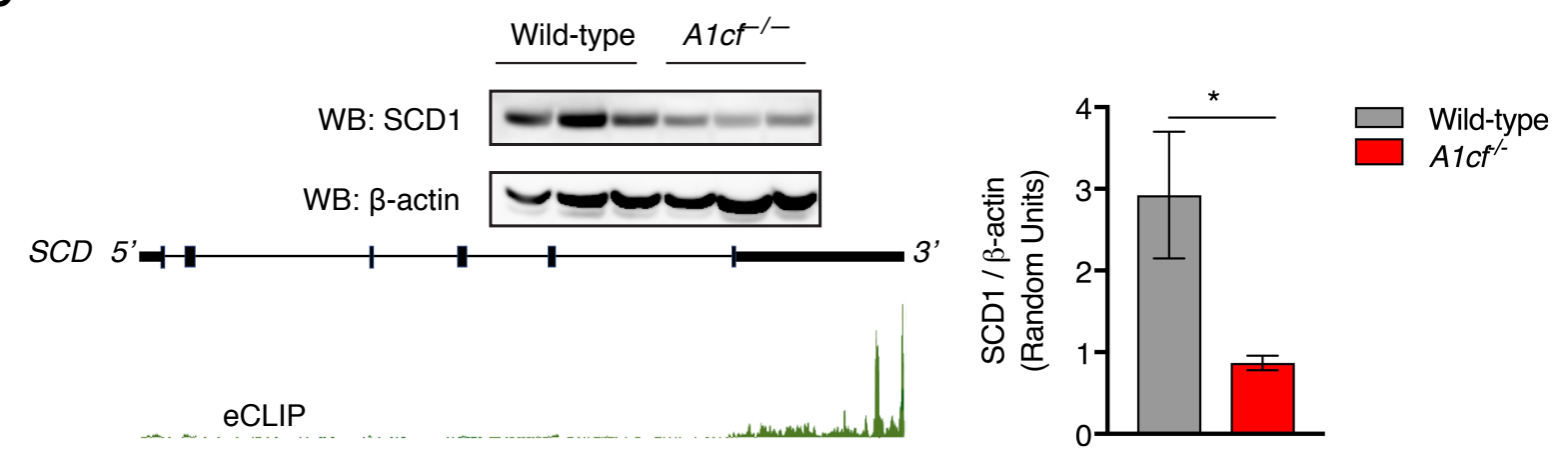

Figure 6. A1CF deficiency alters protein translation of binding targets. (A-C) Immunoblot of mouse livers was performed for $\mathrm{A} 1 \mathrm{CF}$ binding targets $G S R, C P E$, and $S C D$. Representative blots are shown with corresponding densitometry ( $n=3$ per group). eCLIP binding sites for the target transcripts are visualized 5 in green, falling in the 3' UTR region. 